\title{
Hormonal Evidence for Altered Responsiveness to Social Stress in Major Depression
}

Elizabeth A. Young, M.D., Juan F. Lopez, M.D., Virginia Murphy-Weinberg, R.N., M.S., Stanley J. Watson, M.D., Ph.D., and Huda Akil

In patients with major depression, abnormalities in baseline cortisol secretion and resistance to negative feedback are well established. However, it is unclear if patients with major depression have alterations in the hypothalamicpituitary-adrenal (HPA) response to stressors. While other challenges to the HPA axis have used endocrine stimuli such as insulin-induced hypoglycemia, we now report of the response to a social stressor in patients with major depression and matched control subjects. We used the Trier Social Stress Test (TSST), a public speaking task followed by mental arithmetic challenge in front of a panel of judges. The results suggest that depressed patients manifest normal cortisol response to a social stressor, despite increased pre- stressor plasma cortisol. However, the $\beta$-endorphin response to the TSST was significantly smaller in the depressed patients compared to matched controls. These data are similar to data found with exogenous corticotropinreleasing-hormone challenge studies and suggest that elevated baseline cortisol can modulate the pituitary corticotroph response to a stressor, but that changes in adrenal sensitivity to ACTH result in a robust cortisol response to this stressor. [Neuropsychopharmacology 23:411-418, 2000] (C) 2000 American College of Neuropsychopharmacology. Published by Elsevier Science Inc.
KEY WORDS: ACTH; Cortisol; Glucocorticoid feedback; Stress; Depression; HPA axis

Over the last two decades, an extensive body of work has pointed to a close relationship between stress and major depression. Studies by numerous investigators including Frank et al. (1994) and Brown et al. (1994) have documented the role of stressful life events in the precipitation of depressive episodes. Studies in twins by Kendler et al. (1993) have demonstrated a clear interaction between genetic substrate and a recent stressful

From the Department of Psychiatry and Mental Health Research Institute, University of Michigan, Ann Arbor, MI 48109.

Address correspondence to: Elizabeth A. Young, Department of Psychiatry and Mental Health Research Institute, University of Michigan, 205 Zina Pitcher Place, Ann Arbor, MI 48109.

Received August 4, 1999; revised March 28, 2000; accepted April 6, 2000 . life event in the precipitation of a depressive episode. In addition, abnormalities in the hypothalamic-pituitary adrenal (HPA) axis are seen during depression. HPA measures have demonstrated different types of dysregulation at rest or following various endocrine challenges. For example, patients with major depression demonstrate elevated plasma cortisol levels at rest, a finding observed in approximately $50 \%$ of depressed patients. This increase in plasma cortisol is particularly evident in the evening, at the nadir of the circadian rhythm (Sachar et al. 1973; Carroll et al. 1976; Rubin et al. 1987; Halbreich et al. 1985; Pfohl et al. 1985). Furthermore, a number of studies have investigated abnormal glucocorticoid feedback, typically using the synthetic steroid dexamethasone but also using the naturally occurring glucocorticoid cortisol (Carroll et al. 1981; Young et al. 1993, 1991). These studies generally support the view that there is significant dysregulation of 
steroid negative feedback mechanisms in major depression. Fewer studies have examined the activational circuits of the LHPA axis in depression, and these studies have been limited to endocrine challenges such as metyrapone, or insulin-induced hypoglycemia (Young et al. 1994; von Bardeleben et al. 1988; Kathol et al. 1992; Lopez et al. 1987). The metyrapone studies suggested increased central drive in the evening (Young et al. 1994), while insulin-induced hypoglycemia revealed elevated basal cortisol and an attenuated ACTH response to the challenge (Kathol et al. 1992; Lopez et al. 1987). Finally, there is evidence that corticotropin-releasinghormone, $\mathrm{CRH}$, which represents the final common path of stress responsiveness in the brain, is elevated in CSF and hypothalamus, and that this elevation may contribute both to the endocrine and psychological profile seen in severe depression (Nemeroff et al. 1984; Roy et al. 1987; Raadsheer et al. 1995, 1994; Nemeroff, 1988; Nemeroff et al. 1988).

In spite of these findings, it remains difficult to determine what these endocrine changes tell us about the alterations in key neuronal circuits which mediate stress responsiveness and which may contribute either to the onset or to the perpetuation of depression. Assuming that the primary problem in mood disorders resides in the brain above the level of the hypothalamus (which represents the last waystation of the brain response to stress), it is critical to determine if there are basic differences in stress responsiveness in depressed patients that may account for their greater vulnerability to stress- induced depressive episodes as well as the well established endocrine abnormalities. Furthermore, it is critical to use a stressor that activates key emotional circuits, since data in animals suggest that limbic areas of the brain such as the hippocampus are not involved in stress regulation to physiological challenges such as interleukin challenge or hypotension, while these areas are involved in the endocrine response to emotional stressors (Herman and Cullinan 1997). With these considerations in mind, we undertook to study the response to a social stressor under controlled laboratory conditions in depressed subjects in comparison to healthy controls using the Trier Social Stress Test (TSST) (Kirschbaum et al. 1993).

\section{METHODS}

\section{Subject Selection}

The study involved 10 depressed patients, 6 men and 4 women, and 10 normal controls, who were age and sex matched to the patients. An additional eight subjects were studied as part of our initial calibration of the paradigm. The mean age of the patients was $33 \pm 11$ years (S.D.); the mean age of the matched controls was $33.9 \pm$ 11.49 (S.D.) years. All patients presented to the Univer- sity of Michigan Mood Disorder Program for treatment of depression. At the time of study, all patients were untreated for their current depressive episode and agreed to postpone treatment until completion of the study. All patients received a structured interview, the Structured Clinical Interview for DSM-IV (SCID-IV), to confirm the clinical diagnosis of Major Depression. Mean Hamilton Depression Rating Scale (HDRS, 17 item) score at the time of study was $20 \pm 5.6$ (S.D.). Three patients also met DSM-IV criteria for anxiety disorders, two for panic disorder and one for anxiety NOS. Patients with other comorbid Axis I diagnoses were excluded. No patients met criteria for alcohol and substance abuse within the previous 2 years. No patient had a history of childhood abuse, trauma or post-traumatic stress disorder. A urine drug screen was obtained on all patients during the screening and none showed evidence of drug abuse. All controls were screened with the SCID-non patient version to exclude subjects with previous psychiatric disorders. All patients and controls were free of medical illnesses, had normal T4 and TSH hormone levels and were taking no medications including over the counter medication, with the exception of an occasional aspirin or acetominophen.

\section{Study Description}

The protocol was approved by the University of Michigan Hospitals IRB. All studies were conducted in the specialized neuroendocrine research area used for all of our previous neuroendocrine studies. Subjects reported to the research area at 4:00 P.M. and an intravenous catheter was inserted at that time. The subjects were then brought into the conference room where the remainder of the study would occur. At the time of recruitment into the study when they signed the informed consent, the subjects were informed that the task consisted of a public speaking task during which blood samples would be collected for the measurement of stress hormones. Five minutes before the onset of the stressor, the subjects were given a more specific description of the task, which consists of a mock job interview before a panel of judges who rate their behavior. They were informed that the interview would be videotaped. The subjects were to explain why s/he would be the ideal candidate for this job and to enumerate his/ her strengths and qualifications in an unstructured manner (i.e., "sell yourself" to the panel). The job description was matched to each subject based on the subject's own goals and aspirations. The subjects were allowed 5 minutes to prepare for this task. At the onset of the stressor (TSST), the panelists entered the conference room and the subjects began the interview. Following the conclusion of the interview (5 minutes), the subjects were asked to serially subtract 13 from 1022 . After 5 minutes of mental arithmetic, the interview concluded. 
Blood samples were collected for 1 hour following the end of the interview. A total of 14 samples of $21 \mathrm{mls}$ were drawn for a total value of $294 \mathrm{mls}$. To determine the subjective response to the stressor and feelings during the recovery period, $100 \mathrm{~mm}$ line ratings of emotions (talkative, happy, drowsy, nervous, sad, calm, depressed, anxious, energetic, fearful, mellow, high and angry) were collected immediately following the conclusion of the stressor and 20 minutes later. At the end of the blood samplings ( +75 minutes), subjects were debriefed and given the name of a contact person should further questions arise.

\section{Hormonal Assays}

ACTH and $\beta$-endorphin are derived from the same precursor, proopiomenlanocortin, and are co-synthesized and co-secreted. Thus either hormone serves as an index of corticotroph secretion. $\beta$-endorphin immunoreactivity ( $\beta$-endorphin) was assayed using our previously described radioimmunoassay (Cahill et al. 1983). In brief, following collection of blood in pre-chilled EDTA vacutainer tubes, the blood samples were centrifuged immediately, the plasma separated and acidified with $1 \mathrm{~N} \mathrm{HCl}$ to $\mathrm{pH} 2.0$, and frozen on dry ice. Samples were stored at $-80^{\circ} \mathrm{C}$ until extraction using Sep-Pak

\section{B-Endorphin and Cortisol Response to the TSST in Normal Controls $(n=10)$}

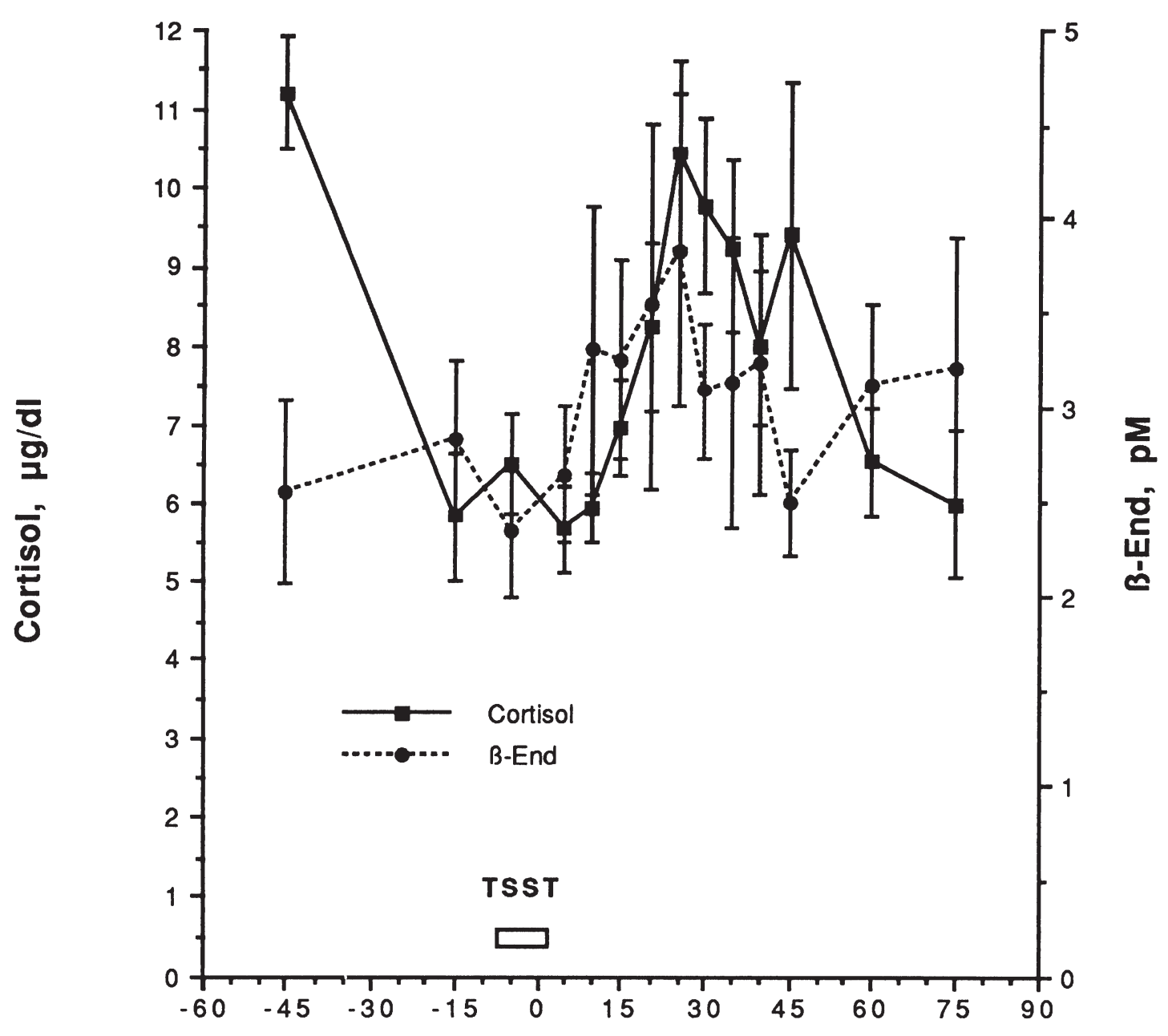

Time, $\min$

Figure 1. The $\beta$-endorphin and cortisol response to the social stressor (TSST) in the 10 control subjects. The data shown are the mean plus standard error of the mean. Both hormones demonstrate a clear response to the stressor, with $\beta$-endorphin response preceding the cortisol response. 
C18 cartridges. The equivalent of $2 \mathrm{ml}$ of extracted plasma was added to each assay tube. The antibody recognizes both the C-terminal fragments of proopiomelanocortin, $\beta$-lipotropin and $\beta$-endorphin, equally and the substance measured is referred to as $\beta$-endorphinIR. ACTH was assayed using the Allegro HS ACTH IRMA from Nichols Institute (San Juan Capistrano, CA). This assay uses unextracted plasma with EDTA used as the anticoagulant. Cortisol was assayed using the DPC Coat-a-Count assay kit.

\section{Data Analysis}

Hormone data was analyzed by examining the integrated area under the curve using a trapezoidal approx- imation. Data from patient and controls were compared by $t$-test after the data were log transformed. Data are presented as mean plus and minus for standard error of the mean. Two-way repeated measure analysis of variance (ANOVA) was used to determine differences between patients and controls and the effect of the stressor on $\beta$-endorphin and cortisol secretion. Baseline hormones and self ratings were compared with twoway repeated measure ANOVA.

Cortisol Response to the TSST

in Patients and Controls

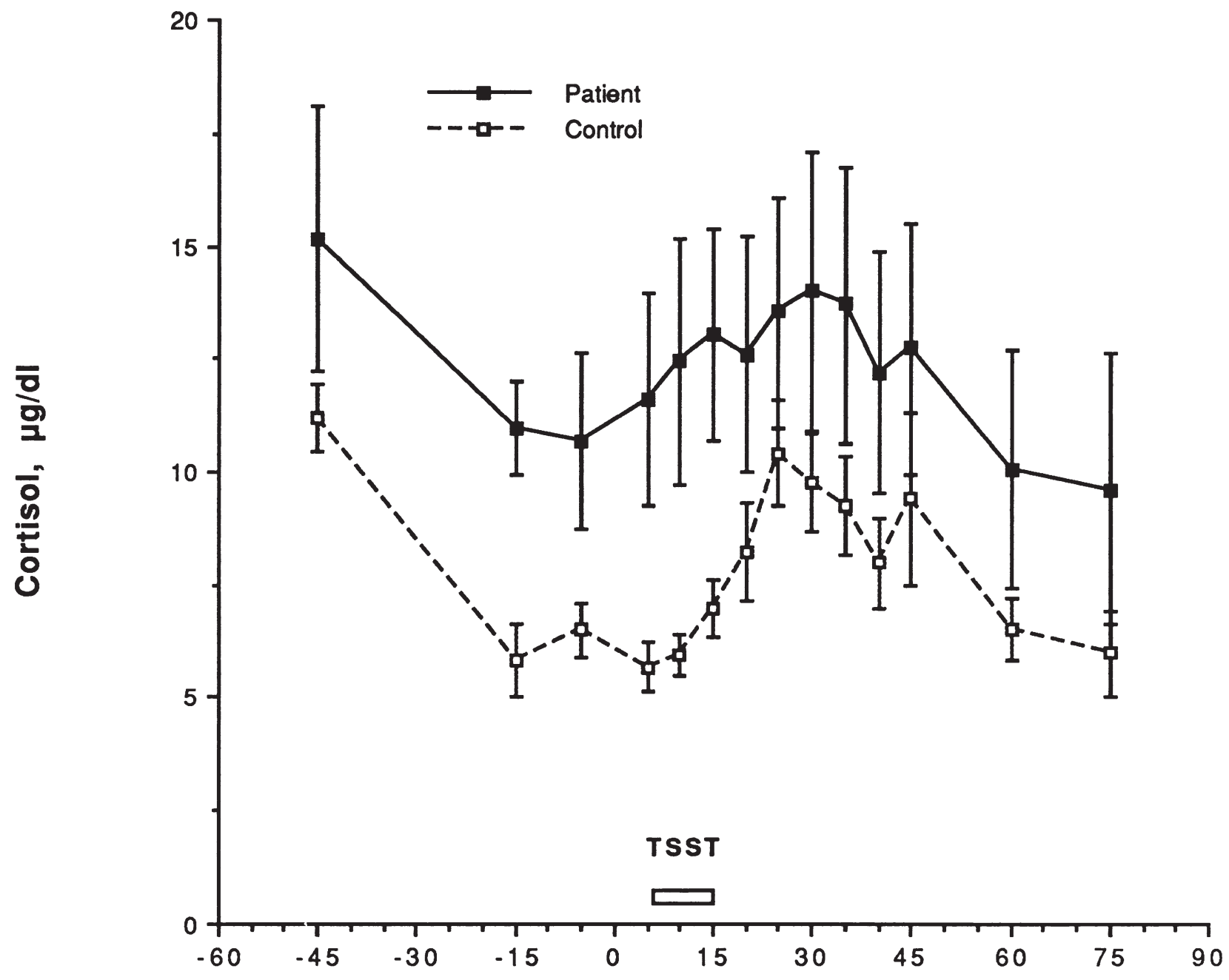

Time, min

Figure 2. Cortisol response to the social stressor (TSST) in depressed patients and control subjects. The data shown are the mean plus standard error of the mean. Note the greatly elevated baseline cortisol in the patients. Despite the high baseline cortisol in the depressed patients, both groups demonstrate similar cortisol responses to the TSST. 
controls for depressed patients. All controls had blood samples drawn for ACTH, $\beta$-endorphin-IR and cortisol, while patients had samples for only $\beta$-endorphin-IR and cortisol. Figure 1 shows the $\beta$-endorphin and cortisol response to TSST in the 10 control subjects. As can be observed, there is a clear increase in both hormones in response to the TSST in normal subjects and the increase in $\beta$-endorphin precedes the increase in cortisol. In control subjects, ACTH and $\beta$-endorphin demonstrated increases following the stressor, although the $\beta$-endorphin response peaked 10 minutes later than the ACTH response (data not shown). To determine the effect of pre-stress cortisol on the response to the TSST, a linear regression of AUC vs. initial cortisol ( $-45 \mathrm{~min}$ utes) was conducted; there was a significant negative relationship ( $\mathrm{r}=-0.7 ; p=0.02)$ in normal controls.

Having demonstrated a robust response to the stressor in normal subjects, the next question is the response of depressed patients to this stressor. Figure 2 shows the cortisol data for the 10 depressed patients and their matched control subjects. Before the task description (onset of the stressor), patients demonstrate higher prestress cortisol than their matched control subjects (RM ANOVA $\mathrm{F}=8.0, \mathrm{df}=1, p=.01$ ). Following the stressor, increases in cortisol are observed for the two groups, although the patients are starting from a much

\section{B-Endorphin Reponse to the TSST in Patients and Controls}

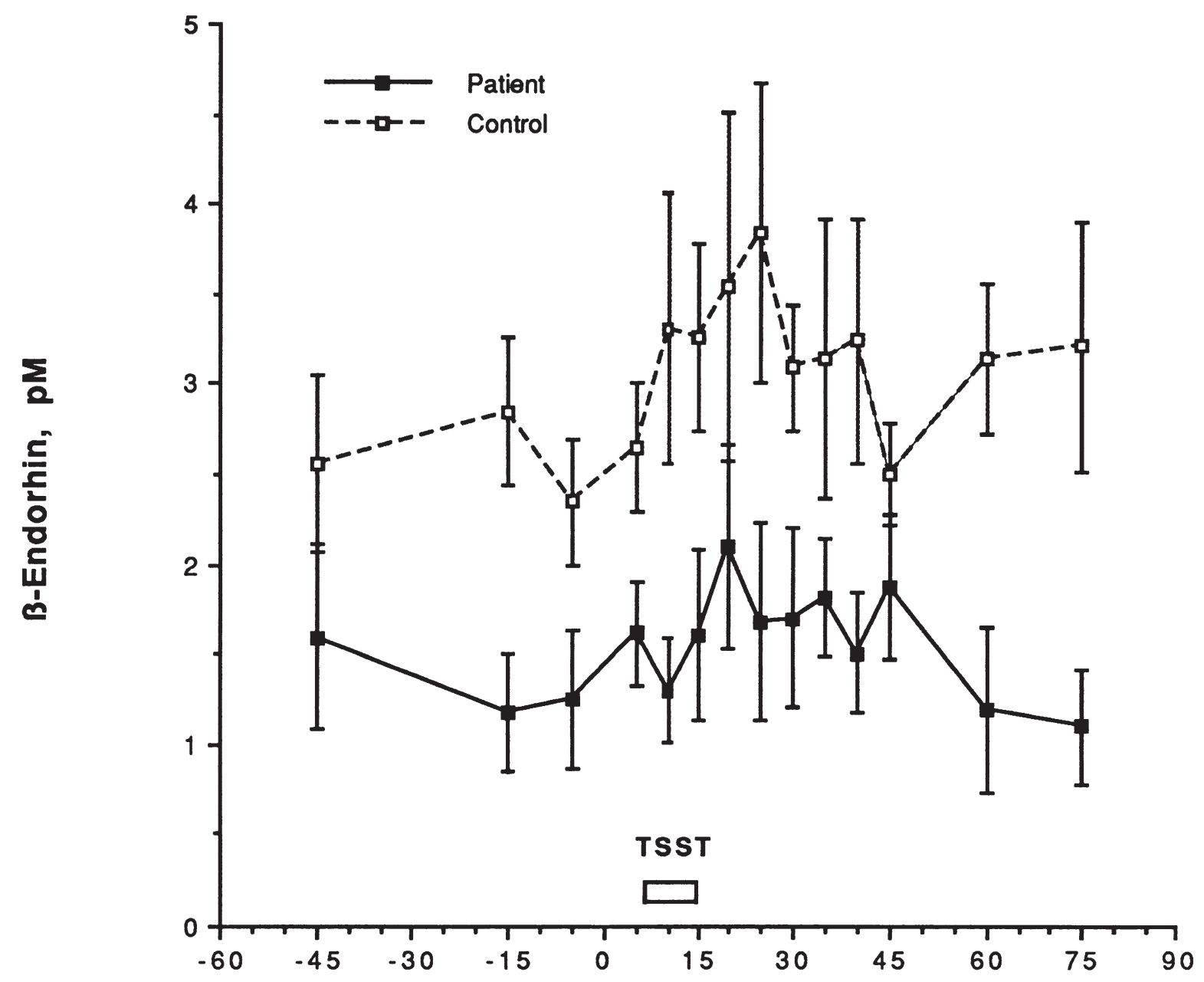

Time, min

Figure 3. $\beta$-endorphin response to the social stressor (TSST) in depressed patients and control subjects. The data shown are the mean plus standard error of the mean. The depressed patients demonstrate lower resting $\beta$-endorphin levels and a smaller response to the stressor. 
higher baseline. The variability in the patient's response to the TSST is greater than the controls, leading to greater standard errors (Figure 2). Overall, the integrated cortisol response (area under the curve, AUC) is similar between patients and controls (patients $=139 \pm$ 39 vs. controls $=122 \pm 44 \mu \mathrm{g} / \mathrm{dl}$.minutes, mean \pm S.E.M., $\log$ transformed AUC $p=0.86$ ). A repeated measure ANOVA of plasma cortisol between -5 and +75 minutes demonstrates a significant effect of the stressor (repeated measures $\mathrm{F}=6.7, \mathrm{df}=11, p=.0001$ ) but no significant difference between patients and controls. In patients, there was no relationship between initial cortisol values and the cortisol response (AUC) to the TSST. The depressed patients demonstrate lower pituitary corticotroph secretion into plasma, as demonstrated by lower plasma $\beta$-endorphin at baseline than their matched controls (Figure 3). Following the stressor, both groups show an increase in $\beta$-endorphin (RM ANOVA $\mathrm{F}=2.2, \mathrm{df}=11, p=.016$ for repeated measure) but the AUC is significantly smaller in patients than controls (patients $=14.9 \pm 8.3$ pM.minutes vs. controls $=68.8 \pm 26$ pM.minutes, $\log$ transformed AUC, $p=0.0056$ ). This smaller $\beta$-endorphin response is likely secondary to the increased baseline cortisol in the patients. Furthermore, as would be expected from the similar cortisol response but smaller $\beta$-endorphin-IR response, the ratio of cortisol to $\beta$-endorphin-IR is greater for the patients than controls (controls $=2.9 \pm 0.3$; patients $=18 \pm 7$, mean \pm S.E.M.).

The behavioral data (Table 1), demonstrate a number of items on which the patients rate themselves significantly higher than the controls immediately following the stressor and 20 minutes later, including depression, anxiety, fearfulness, nervousness, sadness, anger and calm (significantly lower on this item). Happy is the only item that demonstrates an interaction effect; the patients are significantly lower than controls, and the patients increase while the controls do not. Note, however, the increased patient score following the 20minute delay still does not equal the baseline score of the controls.

\section{DISCUSSION}

The main findings of this study are: (1) that depressed patients exhibited a decreased $\beta$-endorphin response to the social stressor but (2) depressed patients exhibited a normal cortisol response to the social stressor. The normal cortisol response in depressed patients occurred despite the elevated baseline cortisol, which should inhibit the cortisol response to the stressor. The expected negative relationship between the initial cortisol and response to the TSST was observed in the control subjects but not in the depressed patients. However, the increased pre-stress cortisol levels in the depressed subjects led to the expected decrease in corticotroph secretion, as reflected by plasma $\beta$-endorphin. The extent to which this smaller $\beta$-endorphin response to the stressor in depressed patients occurs because of increased negative feedback at the pituitary vs. increased negative feedback at the hypothalamus is not known, since we cannot measure CRH secretion into the hypophyseal portal blood of humans. However, studies with administration of a dose of exogenous $\mathrm{CRH}$ have demonstrated a similar endocrine response pattern to what we have demonstrated with this stressor, that is a blunted ACTH or $\beta$-endorphin response but a normal cortisol response to a standardized dose of $\mathrm{CRH}$ in depressed subjects (Gold et al. 1986; Holsboer et al. 1984; Young et al. 1990). This suggests that the central CRH response in these depressed patients could be equivalent in the de-

Table 1. Behavioral Response to the TSST

\begin{tabular}{lccccc}
\hline & \multicolumn{2}{c}{ Controls } & & \multicolumn{2}{c}{ Patients } \\
\cline { 2 - 3 } \cline { 5 - 6 } & End of TSST & 20 Minutes Later & & End of TSST & 20 Minutes Later \\
\hline Talkative & $48.6 \pm 7$ & $42.3 \pm 6.8$ & & $47.6 \pm 8.6$ & $31 \pm 5.3$ \\
Happy & $50.9 \pm 3.88$ & $51.6 \pm 4$ & & $18.6 \pm 5.25$ & $34.9 \pm 8^{*, * *}$ \\
Drowsy & $35.4 \pm 8.8$ & $29.1 \pm 8.3$ & & $42.4 \pm 7.7$ & $37.4 \pm 6$ \\
Nervous & $36.8 \pm 5.3$ & $12.5 \pm 4.7$ & & $66 \pm 5.4$ & $31.9 \pm 4.8^{*}$ \\
Sad & $8.5 \pm 3.2$ & $7 \pm 2.7$ & & $41.6 \pm 9.8$ & $38.3 \pm 9.6^{*}$ \\
Calm & $41.3 \pm 5$ & $64.3 \pm 7.3$ & & $37.9 \pm 8.9$ & $44 \pm 5^{*}$ \\
Depressed & $4.1 \pm 0.6$ & $3.9 \pm 1.4$ & & $37.4 \pm 6.1$ & $33.4 \pm 4.6^{*}$ \\
Anxious & $34 \pm 5.7$ & $14.6 \pm 5.1$ & & $55.3 \pm 5.8$ & $29.6 \pm 5.8^{*}$ \\
Energetic & $54.4 \pm 7$ & $33.4 \pm 6.1$ & & $33.7 \pm 8.2$ & $30.7 \pm 6.0$ \\
Fearful & $3 \pm 0.75$ & $7.6 \pm 5.4$ & & $29.4 \pm 9.1$ & $20 \pm 5.6^{*}$ \\
Mellow & $33.5 \pm 6$ & $42.6 \pm 7.4$ & & $23.4 \pm 5.6$ & $39.4 \pm 7.8$ \\
High & $22.5 \pm 7.5$ & $26.7 \pm 6.6$ & & $24.7 \pm 8.6$ & $22.3 \pm 6$ \\
Angry & $10.4 \pm 4.2$ & $7.1 \pm 3.2$ & & $38 \pm 11.9$ & $24.9 \pm 10.5^{*}$ \\
\hline
\end{tabular}

${ }^{*} p<.05$ patients vs. controls by two-way repeated measure ANOVA.

${ }^{* *} p<.05$ interaction between group and time by two-way repeated measure ANOVA. 
pressed and control subjects. Furthermore, the finding of a blunted $\beta$-endorphin response with a normal cortisol response suggests increased sensitivity of the adrenal to ACTH in depressed patients. Similar findings are seen following CRH administration (Gold et al. 1986; Holsboer et al. 1984; Young et al. 1990). Nevertheless, given the high levels of cortisol at the start of the session in depressed patients, it can be argued that the depressed subjects show an inappropriately large cortisol stress response and resistance to the negative feedback effects of their baseline cortisol on subsequent cortisol secretion. Thus the patients demonstrate the persistence of a robust cortisol response to this social stressor despite the elevated baseline cortisol. Since cortisol is the main regulated end product of the HPA axis and it acts upon multiple systems of the brain, the persistence of a normal cortisol response in the face of elevated cortisol could have multiple consequences for the organism and further exacerbates the hypercortisolemia of depression. The resistance to the negative feedback effects of glucocorticoids seen with this stressor are in agreement with studies of dexamethasone glucocorticoid negative feedback using cortisol infusion challenges (Carroll et al. 1981; Young et al. 1991). Finally, several studies have examined the cortisol response to a cognitive stressor in depressed patients, and found elevated pre-stress cortisol but a smaller cortisol response to the cognitive challenge in the depressed patients compared to control subjects. (Trestman et al. 1991; Gotthardt et al. 1995). It should be noted that the cortisol responses to the cognitive stressors in normal subjects in these studies were much smaller than what we observed with the TSST. Nonetheless, taken together these data and ours suggest differences in the cortisol response between depressed patients and controls to a stressor that activates emotional circuits versus a purely cognitive stressor.

In conclusion, we report the first study to our knowledge of patients with major depression examining a social stressor, the TSST. These patients demonstrated increased plasma cortisol levels in advance of the stressor, but a normal cortisol response (AUC) despite the already high resting cortisol. The depressed patients also demonstrated a significantly smaller corticotroph response as measured by plasma $\beta$-endorphin. The finding of a decreased corticotroph response to a social stressor observed here is similar to the response observed in studies with exogenous CRH or insulininduced hypoglycemia in depressed patients. However, the failure to measure ACTH as well as $\beta$-endorphin is a clear limitation of the current study. However, our endocrine data are consistent with what has been shown in terms of pituitary adrenal responsiveness when endocrine stimuli are used as challenges. Given the data on response to exogenous CRH in depression, the normal cortisol response likely results from increased adrenal sensitivity to ACTH. The preservation of a normal cortisol response to a stressor despite increased prestress cortisol levels, suggest that part of the endocrine pathophysiology of depressed patients may involve the continual responding to everyday life stressors. In fact, the pre-stress cortisol levels observed in depressed patients already involve the response to the stress of coming into the research laboratory setting for a challenge. Finally, failure to restrain cortisol secretion in response to a stressor in the face of already elevated cortisol may result in greater overall cortisol exposure in depressed patients leading to changes in mood and cognition and thus exacerbate the depressive condition (Wolkowitz 1994; Starkman and Schteingart 1981; Starkman et al. 1992).

\section{ACKNOWLEDGMENTS}

The authors acknowledge support of MH 00427 to EY, MH 01164 to JFL, MH 42251 to SJW and HA, MO1 RR00042 (general CRC), P30 HD18258 Assay and Reagents Core, and Dirk Hellhammer for instruction on the specific methods of the Trier Social Stress Test.

\section{REFERENCES}

Brown GW, Harris TO, Hepworth C (1994): Life events and endogenous depression. A puzzle reexamined. Arch Gen Psychiatry 51:525-534

Cahill CA, Matthews JD, Akil H (1983): Human plasma betaendorphin-like peptides: A rapid high recovery extraction technique and validation of radioimmunoassay. J Clin Endocrinol Metab 56:992-997

Carroll BJ, Curtis GC, Mendels J. Neuroendocrine regulation in depression I (1976): Limbic system-adrenocortical dysfunction. Arch Gen Psychiatry 33:1039-1044

Carroll BJ, Feinberg M, Greden JF, Tarika J, Albala AA, Haskett RF, James N, Kronfol Z, Lohr N, Steiner M, DeVigne JP, Young EA (1981): A specific laboratory test for the diagnosis of melancholia. Arch Gen Psychiatry 38(1):15-22

Frank E, Anderson B, Reynolds CF, Ritenour A, Kupfer DJ (1994): Life events and the research diagnostic criteria endogenous subtype. A confirmation of the distinction using the Bedford College methods. Arch Gen Psychiatry 51:519-524

Gold PW, Loriaux DL, Roy A, Kling MA, Calabrese JR, Kellner CH, Nieman LK, Post RM, Pickar D, Gallucci W (1986): Response to corticotropin-releasing hormone in the hypercortisolism of depression and Cushing's disease. N Engl J Med 314:1329-1335

Gotthardt U, Schweiger U, Fahrengerg J, Lauer CJ, Holsboer F, Heuser I (1995): Cortisol, ACTH, and cardiovascular response to a cognitive paradigm in aging and depression. Am J Physiol 268:R865-R873

Halbreich U, Asnis GM, Schindledecker R, Zurnoff B, Nathan RS (1985): Cortisol secretion in endogenous depression I. Basal plasma levels. Arch Gen Psychiatry 42:909-914 
Herman JP, Cullinan WE (1997): Neurocircuitry of stress: Central control of the hypothalamo-pituitary-adrenocortical axis. Trends Neurosci 20:78-84

Holsboer F, Bardeleden U, Gerken A, Stalla G, Muller O (1984): Blunted corticotropin and normal cortisol response to human corticotropin-releasing factor in depression. N Engl J Med 311:1127

Kathol RG, Gehris TL, Carroll BT, Samuelson SD, Pitts AF, Meller WH, Carter JL (1992): Blunted ACTH response to hypoglycemic stress in depressed patients but not in patients with schizophrenia. J Psychiatric Research 26:103-116

Kendler KS, Kessler RC, Neale MC, Heath AC, Eaves LJ (1993): The prediction of major depression in women: Toward an integrated etiological model. Am J Psychiatry 150:1139-1148

Kirschbaum C, Pirke KM, Hellhammer DH (1993): The "Trier Social Stress Test" - a tool for investigating psychobiological stress responses in a laboratory setting. Neuropsychobiology 28(1-2):76-81

Lopez JF, Kathol RG, Jaeckle RS, Meller W (1987): The HPA axis response to insulin hypoglycemia in depression. Biological Psychiatry 22:153-166

Nemeroff CB (1988): The role of corticotropin-releasing hormone in the pathogenesis of major depression. Pharmacopsychiatry 21:76-82

Nemeroff CB, Owens MJ, Bissette G, Andorn AC, Stanley M (1988): Reduced corticotropin releasing factor binding sites in the frontal cortex of suicide victims. Arch Gen Psychiatry 45:577-579

Nemeroff CB, Widerlov E, Bisette G, Walleus H, Karlsson I, Eklund K, Kilts CD, Loosen PT, Vale W (1984): Elevated concentrations of CSF Corticotropin-releasing-factorlike immunoreactivity in depressed patients. Science 226:1342-1344

Pfohl B, Sherman B, Schlecte J, Stone R (1985): Pituitary/ adrenal axis rhythm disturbances in psychiatric patients. Arch Gen Psychiatry 42:897-903

Raadsheer FC, Hoogendijk WJ, Stam FC, Tilders FJ, Swaab DF (1994): Increased numbers of corticotropin-releasing hormone expressing neurons in the hypothalamic paraventricular nucleus of depressed patients. Neuroendocrinology 60:436-444

Raadsheer FC, van Heerikhuize JJ, Lucassen PJ, Hoogendijk WJ, Tilders FJ, Swaab DF (1995): Corticotropin-releasing hormone mRNA levels in the paraventricular nucleus of patients with Alzheimer's disease and depression. Am J Psychiatry 152:1372-1376
Roy A, Pickar D, Paul S, Doran A, Chrousos GP, Gold PW (1987): CSF corticotropin-releasing hormone in depressed patients and normal control subjects. Am J Psychiatry 144(5):641-645

Rubin RT, Poland RE, Lesser IM, Winston RA, Blodgett N (1987): Neuroendocrine aspects of primary endogenous depression I. Cortisol secretory dynamics in patients and matched controls. Arch Gen Psychiatry 44:328-336

Sachar EJ, Hellman L, Roffwarg HP, Halpern FS, Fukush DK, Gallagher TF (1973): Disrupted 24 hour patterns of cortisol secretion in psychotic depressives. Arch Gen Psychiatry 28:19-24

Starkman MN, Gebarski SS, Berent S, Schteingart DE (1992): Hippocampal formation volume, memory dysfunction, and cortisol levels in patients with Cushing's syndrome. Biological Psychiatry 32:756-765

Starkman MN, Schteingart DE (1981): Neuropsychiatric manifestations of patients with Cushing's syndrome. Relationship to cortisol and adrenocorticotropic hormone levels. Arch Intern Med 141:215-219

Trestman RL, Coccaro EF, Bernstein D, Lawrence T, Gabriel SM, Horvath TB, Siever LJ (1991): Cortisol responses to mental arithmetic in acute and remitted depression. Biol Psychiatry 29:1051-1054

von Bardeleben U, Stalla GK, Mueller OA, Holsboer F (1988): Blunting of $\mathrm{ACTH}$ response to $\mathrm{CRH}$ in depressed patients is avoided by metyrapone pretreatment. Biol Psychiatry 24:782-786

Wolkowitz OM (1994): Prospective controlled studies of the behavioral and biological effects of exogenous corticosteroids. Psychoneuroendocrinology 19:233-256

Young EA, Watson SJ, Kotun J, Haskett RF, Grunhaus L, Murphy-Weinberg V, Vale W, Rivier J, Akil H (1990): Response to low dose oCRH in endogenous depression: Role of cortisol feedback. Arch Gen Psychiatry 47:449457

Young EA, Haskett RF, Watson SJ, Akil H (1991): Loss of glucocorticoid fast feedback in depression. Arch Gen Psychiatry 48:693-699

Young EA, Kotun J, Haskett RF, Grunhaus L, Greden JF, Watson SJ, Akil H (1993): Dissociation between pituitary and adrenal suppression to dexamethasone in depression. Arch Gen Psychiatry 50:395-403

Young EA, Haskett RF, Grunhaus L Pande A, MurphyWeinberg V, Watson SJ, Akil H (1994): Increased circadian activation of the hypothalamic pituitary adrenal axis in depressed patients in the evening. Arch Gen Psychiatry 51:701-707 